\title{
Behandling av fraktur i handrota
}

\author{
Samandrag \\ Bakgrunn. Målet med denne studien \\ var å finne førekomsten og behandlinga \\ av pasientar med handrotsfraktur ved \\ Ortopedisk seksjon, Haugesund sjuke- \\ hus.
}

\begin{abstract}
Materiale og metode. Totalt 320 pasientar med 331 karpale frakturar som vart behandla ved seksjonen, var inkluderte i studien. Data blei samla inn ved journalgjennomgang.
\end{abstract}

Resultat. 277 pasientar fekk påvist ein skafoidfraktur og sluttresultatet var tilheling hos $96 \%$. Adekvat og rask behandling av 243 skafoide frakturar med gipsimmobilisering eller primær operasjon gav tilheling hos $89 \%$ av disse. Etter operativ behandling for manglande tilheling var sluttresultatet tilheling hos $99 \%$. 34 pasientar fekk inadekvat eller for sein primær behandling, og sluttresultatet etter gipsing, operasjonar for manglande tilheling og ein reoperasjon i denne gruppa var tilheling hos berre $75 \%$. Inadekvat eller forseinka primær behandling medførte signifikant auka frekvens av manglande tilheling og operasjon. Alle 54 ikkje-skafoide frakturar tilhela tilfredsstillande og berre ein blei operert. 27 pasientar hadde fraktur av os triquetrum. Det var sjeldan fraktur i dei seks andre handrotsbeina.

Tolking. Resultatet av gipsing og primær operasjon var tilfredsstillande. Våre resultat samsvarer stort sett med andre rapportar frå litteraturen.

\section{Birger Valen}

birger.valen@helse-fonna.no

Ortopedisk seksjon

Haugesund sjukehus

5504 Haugesund

Skafoidfraktur i handleddet er ein vanleg tilstand og utan samanlikning den vanlegaste frakturen av handrotsbeina. Handrota inneheld sju andre bein som også kan brekke. Slike skadar er sjeldne, men bør bli vurderte ved skade eller smerter i handleddet. Frakturane kan ha alle grader av dislokasjon og gir ofte lite smerter slik at skaden lett kan bli oversett. Det er som regel ikkje ødem eller klinisk feilstilling. Det er derfor grunn til å rekne med at denne typen fraktur er underdiagnostisert $(1,2)$. Skaden har god prognose viss den blir oppdaga og adekvat behandla og dårleg prognose viss den blir oversett. Den er derfor interessant også i erstatningssamanheng.

Skademekanisme er oftast eit fall på utstrekt arm med dorsalfleksjon og radial- eller ulnardeviasjon i handleddet. Anatomisk er det mange variantar frå små avulsjonsfrakturar til fraktur tvers gjennom corpus. Frakturen kan også vere kombinert med fraktur eller dislokasjon i fleire handrotsbein eller med fraktur i radius eller metakarpane (3). Diagnosen er ofte usikker. Gipsing pga. mistanke medfører initial overbehandling av denne pasientgruppa, og tidleg kontroll med spesialbilete er derfor nødvendig. Dette vil i fleirtalet av tilfella avkrefte mistanken om skafoidfraktur eller påvise fraktur i andre handrotsbein $(1,4,5)$.

Da frakturen kan vere vanskeleg å oppdage på vanlege røntgenbilete, kan det vere nødvendig med spesialbilete, som CT eller $\operatorname{MR}(1,3,5,6)$, eller å samanlikne med røntgenbilete av den friske handa. Disse pasientane kan også vere kandidatar for handleddsartroskopi.

Standard behandling er primært immobilisering med gips viss frakturen er udislosert og operativ behandling med reponering og osteosyntese ved nemneverdig feilstilling, og det er viktig å oppnå anatomisk stilling (2, 6). Ved operasjon av ikkje-skafoide frakturar blir det ofte brukt pinning, og mindre fragment utan leddaffeksjon kan ofte fjernast.

Inadekvat primær behandling av alle typar karpale frakturar kan gi pseudartrose og $i$ andre omgang artrose $i$ handleddet (2). Korrekt pseudartrosebehandling med skruefiksering og eventuell beintransplantasjon er viktig for å unngå seinfølge, som handleddsartrose.

Målet med denne oppfølginga var som ledd i kvalitetssikring å kartlegge førekomst og behandling av karpale frakturar ved vår avdeling.

\section{Materiale og metode}

Materialet er 320 pasientar med 331 karpalfrakturar som alle blei behandla ved Ortopedisk seksjon, Haugesund Sjukehus frå 1987 til og med 2007. $73 \%$ var menn og $27 \%$ var kvinner. Gjennomsnittsalder ved skadetidspunktet var 36,3 år (variasjon 10,1-95,9 år). $48 \%$ hadde fraktur på høgre side og $52 \%$ på venstre. $80 \%$ hadde fall som skademekanisme og resten forskjellige former for klemskade eller trafikkulukker. Kvinner hadde signifikant oftare enn menn fall som skademekanisme $(90 \%$ mot $76 \%, p=0,008)$. Det var kjønnsskilnad $\mathrm{i}$ vårt materiale. Menn var signifikant yngre enn kvinner (33,0 år mot 44,8 år; $\mathrm{p}<0,001$ ), hadde oftare fraktur på høgre side og måtte oftare opererast. Sju pasientar hadde fraktur i to handrotsbein og to pasientar i tre. 16 pasientar hadde tilleggspatologiske tilhøve, som inkluderte ti med fraktur $i$ radius, fem med fraktur av metakarp og to med lunatumluksasjon.

Som primær behandling for skafoide frakturar er det brukt gipsing inklusive tommelfingerens grunnfalang hos alle unntatt dei som blei opererte nesten med ein gong pga. stor feilstilling. Som operasjonsmetode blei det brukt open reponering og skruefiksering med beintransplantasjon i tillegg for pseudartrose. Alle udislokerte ikkje-skafoide frakturar er vanlegvis behandla med gipsimmobilisering i 4-6 veker. Ved feilstilling over $1 \mathrm{~mm}$ er det gjort open reponering, pinning og gipsing unntatt for dislokerte triquetrumfragment.

\section{Hovudbodskap}

- Handrotsfrakturar blir ofte oversette både klinisk og røntgenologisk

- Om lag $80 \%$ av karpale frakturar er skafoide

- For sein behandling av skafoide frakturar gir ofte pseudartrose

- Triquetreumfrakturar utgjer om lag $50 \%$ av dei ikkje-skafoide, og frakturar i dei andre seks handrotsbeina er uvanleg 

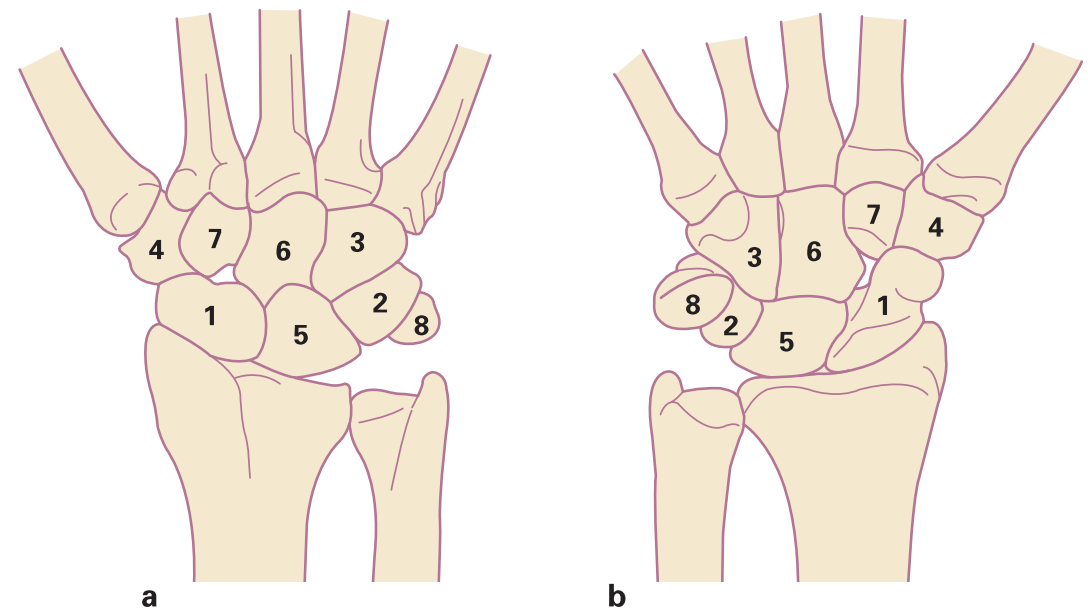

\begin{tabular}{lrc}
\multicolumn{1}{c}{ Knokkel } & Antall & Prosent \\
1. Os scaphoideum & 277 & 83,7 \\
2. Os triquetrum & 27 & 8,2 \\
3. Os hamatum & 8 & 2,4 \\
4. Os trapezium & 7 & 2,1 \\
5. Os lunatum & 7 & 2,1 \\
6 Os capitatum & 4 & 1,2 \\
7. Os trapezoideum & 1 & 0,3 \\
8. Os pisiforme & 0 & 0,0
\end{tabular}

Figur 1 Fordeling av 331 frakturar i karpale bein. a) Handrota sett frå handryggsida. b) Sett frå undersida

Opplysningane er frå gjennomgang av journal og er statistisk bearbeidde ved bruk av programpakken Statistica for Windows (7). Som statistisk signifikant er $\mathrm{p}<0,05 \mathrm{ved}$ både t-test og i krysstabellar.

\section{Resultat}

Fordelinga av lokalisasjon framgår av figur 1. 277 pasientar eller om lag $87 \%$ hadde ein fraktur av os scaphoideum. 243 fekk adekvat behandling, 229 med berre immobilisering og 14 med primær operasjon pga. for stor feilstilling. Dette gav primært tilheling hos $89 \%$ i denne gruppa. Etter 22 operasjonar og tre reoperasjonar var sluttresultatet i denne gruppa at $98,7 \%$ tilhela. 34 andre pasientar med skafoidfraktur fekk forseinka behandling, anten fordi pasienten sjølv ignorerte skaden eller fordi skaden i første omgang blei feilvurdert av andre. Enkelte gjekk fleire år utan behandling. Etter 21 operasjonar og ein reoperasjon for manglande tilheling var sluttresultatet signifikant dårlegare tilheling for denne gruppa $(75 \%$ mot $99 \%, \mathrm{p}<0,001)$. Fem pasientar (2\%) med skafoidfraktur fekk påvist radiokarpal artrose som seinfølge. Gruppa som fekk forsinka behandling, fekk også påvist signifikant oftare radiokarpal artrose $(9 \%$ mot $1 \%, \mathrm{p}=0,001)$.

Alle ikkje-skafoide frakturar blei behandla med gipsing unntatt ein hamatumfraktur som er operert med reponering og pinning. Det var tilfredsstillande tilheling av alle ikkjeskafoide. Manglande tilheling av eit triquetrumfragment blei akseptert som tilfredsstillande. Ingen radiokarpal artrose blei påvist i denne gruppa.

\section{Diskusjon}

Lokalisasjonen til karpale frakturar i vårt materiale (tab 1) samsvarer stort sett med andre rapportar $(2,5,8)$. For skafoide samsvarer alders- og kjønnsfordeling på pasientane $\mathrm{i}$ vårt materiale godt med data $\mathrm{i}$ andre arbeid $(9,10)$. Rutinebehandlinga vår med- fører gipsing av tommelfingerens grunnledd. Om det er nødvendig å gipse inn tommelens grunnledd eller om det er nødvendig med høg gips på overarmen, er omdiskutert (11). At berre gipsing gir tilheling hos om lag $90 \%$ av pasientane med udislokerte frakturar, samsvarer med andre studiar $(4,12)$.

Forseinka behandling av skafoide frakturar medførte $\mathrm{i}$ vår studie mangedobling $\mathrm{av}$ manglande tilheling og pseudartroseutvikling. Dette samsvarer også med andre studiar $(1,4)$. At om lag 20-25\% får manglande tilheling eller pseudartrose, samsvarer om lag med andre resultat $(10,13)$. Pseudartrose gir ofte få symptom, og enkelte meiner at asymptomatiske og tilfeldig oppdaga skafoide pseudartroser kan forbli ubehandla (5). Andre tilrår operasjon også av symptomfrie pseudartroser for å hindre utvikling av radiokarpal artrose $(4,13)$. For denne tilstanden er det ofte lite samsvar mellom røntgenbilete og kliniske funn (10).

Vi har brukt skruefiksering som primærbehandling ved dislokerte skafoide frakturar (over $1 \mathrm{~mm}$ diastase) og gipsing i tillegg. Skruefiksering kan også bli gjort med perkutan teknikk (14) eller med ein kombinasjon av perkutan og endoskopisk teknikk (15). Operasjon kan bli gjort både frå volar- og dorsalsida (16).

Vi fann 27 pasientar med fraktur i os triquetrum, noko som er nest vanlegast også i andre rapportar $(2,5,8)$. Avulsjonsfraktur utan leddaffeksjon er det vanlege, og eit dislokert fragment kan fjernast viss det gir plager (2). Fraktur i corpus er sjeldan, men kan oppstå ved større skadar som lunatumdislokasjon $(2,8)$. Spesialbilete er ofte nødvendig for å oppdage slik skade (2). Vi hadde ein pasient med forbigåande ulnarisutfall. Os triquetrum ligg også anatomisk i nær relasjon til os pisiforme, og skade kan medføre artrose i leddflata mellom disse (2). Åtte hadde hamatumfraktur og ein blei operert. Han hadde fraktur i corpus med samtidig skade av 4. metakarp. Reponering, pinning og gipsing gav god tilheling. Det er vanleg at hamatumfraktur er kombinert med skade i 4. og 5. metakarp (2). Frakturar i os hamatum er uvanleg, og dreier seg ofte om avriving av hamulus (8). Dette er ofte ein idrettsskade (stressfraktur) og treng ofte inga reponering (2). Det avrivne hamulusfragmentet kan affisere ulnarisnerven og kan fjernast viss det gir symptom. Hamatum har anatomisk nær relasjon til både ulnaris- og medianusnerven forutan fleksorsenane som alle kan bli skadde av eit dislokert fragment $(2,5,8)$.

Sju hadde tarpeziumfraktur som er nummer tre i andre studiar $(2,5,8)$. Slike skadar kan omfatte ein del av leddflata mot 1 . metakarp og resultere $i$ artrose som er ein vanleg komplikasjon $(2,5,8)$. Fraktur i corpus er sjeldan (5) og kan ha nær relasjon til a. radialis som også kan bli skadd (2).

Sju pasientar hadde lunatumfraktur, som er sjeldan (5). Dei kan vere vanskelege å oppdage på røntgen (8) og kan enkelte gonger resultere i avaskulær nekrose eller lunatummalasi pga. devaskularisering $(2,5)$. Dei bør derfor bli etterkontrollerte med MR (2, 8).

Os capitatum er det største karpale beinet og er godt verna midt inne $i$ handleddet. Frakturar oppstår derfor svært sjeldan og er ofte ledd i kombinerte skadar som lunatumluksasjon $(2,5)$. Skaden medfører fare for både pseudartrose, osteonekrose og artrose $(2,5,8)$.

Os trapezoideum ligg også godt verna anatomisk og frakturar førekommer svært sjeldan og er ofte kombinerte med skade av 2. metakarp $(2,8)$. Også her er det viktig å rekonstruere leddflatene anatomisk for å unngå artrose.

Ingen fraktur i os pisiforme blei registrert i vårt materiale. Disse er også svært sjeldne og er ofte idrettsskadar $(5,8)$. Os pisiforme er eit lett palpabelt sesambein og i nær relasjon til fleksor carpi ulnaris-senen. Heile os 
pisiforme kan fjernast viss skaden resulterer i vedvarande smerteplager $(2,5,8)$. Fjerning gir lite funksjonelt utslag.

Vi hadde ingen pasientar under ti år, og dette samsvarer med at karpale frakturar er uvanleg hos barn $(5,17)$.

Oppgitte interessekonflikter: Ingen

\section{Litteratur}

1. Roolker W, Maas M, Broekhuizen AH. Diagnosis and treatment of scaphoid fractures, can nonunion be prevented? Arch Orthop Trauma Surg 1999; 119: 428-31.

2. Papp S. Carpal bone fractures. Orthop Clin North Am 2007: 38: 251-60.

3. Cohen MS. Fractures of the carpal bones. Hand Clin 1997; 13: 587-99

4. Thorleifsson R, Karlsson J, Sigurjonsson K. Fractures of the scaphoid bone. A follow-up study. Arch Orthop Trauma Surg 1984; 103: $96-9$

5. Amadio PC, Taleisnik J. Fractures of the carpal bones. I: Green DP. Operative hand surgery. Bd. I. New York: Churchill Livingstone, 1993.
6. Vigler M, Aviles A, Lee SK. Carpal fractures excluding the scaphoid. Hand Clin 2006; 22 $501-16$.

7. Statistica for Windows. Versjon 8 B. Tusla, OK: Stat Soft, 2008.

8. Gaebler C. Fractures and dislocations of the carpus. I: Rockwood and Green, red. Fractures in adults. Bd. 1. Philadelphia, PA: Lippincott Williams \& Wilkins, 2006.

9. Hove LM. Epidemiology of scaphoid fractures in Bergen; Norway. Scand J Plast Reconstr Surg Hand 1999; 33: 423-6.

10. Duppe H, Johnell O, Lundborg G et al. Long-term results of fracture of the scaphoid. A follow-up study of more than thirty years. J Bone Joint Surg Am 1994; 76: 249-52.

11. Clay NR, Dias JJ, Costigan PS et al. Need the thumb be immobilised in scaphoid fractures? A randomised prospective trial. J Bone Joint Surg $\mathrm{Br}$ 1991; 73: 828-32

12. Saeden B, Tornkvist H, Ponzer S et al. Fracture of the carpal scaphoid. A prospective, randomised 12-year follow-up comparing operative and conservative treatment. J Bone Joint Surg Br 2001; 83 ; $230-4$.

13. Prosser $\mathrm{GH}$, Isbister ES. The presentation of scaphoid non-union. Injury 2003; 34: 65-7.
14. Bond CD, Shin AY, McBride MT et al. Percutaneous screw fixation od cast immobilization for nondisplaced scaphoid fractures. J Bone Joint Surg Am 2001; 84: 483-8.

15. Slade JF 3rd, Gutow AP, Geissler WB. Percutaneous internal fixation of scaphoid fractures via an arthroscopically assisted dorsal approach. J Bone Joint Surg Am 2001; 84 (suppl 2): 21-36.

16. Polsky MB, Kozin SH, Porter ST et al. Scaphoid fractures: dorsal versus volar approach. Orthopedics 2002; 25: 817-9.

17. Christodoulou AG, Colton CL. Scaphoid fractures in children. J Pediatr Orthop 1986; 6: 37-9.

Manuskriptet ble mottatt 3.12. 2007 og godkjent 26.6. 2008. Medisinsk redaktør Kjetil Søreide. 